\title{
Tendencias de investigación en la licenciatura en educación básica con énfasis en humanidades y lengua castellana a nivel nacional desde el año 2011 a $2013^{1}$
}

\author{
Ana Lucía Cañón Moreno² \\ David Jacobo Viveros Granja ${ }^{3}$
}

Fecha de recepción: 26 de abril de 2015

Fecha de revisión: 28 de mayo de 2015

Fecha de aprobación: 12 de junio de 2015

\section{Resumen}

Este artículo presenta el proyecto "Tendencias de investigación en la Licenciatura en Educación Básica con énfasis en Humanidades y Lengua Castellana a nivel nacional desde el año 2011 a 2013", que surgió de la necesidad de reconocer la investigación formativa de este programa y contribuir en la transformación de la Licenciatura de la Universidad Santo Tomás, atendiendo al hecho de que los programas de Licenciatura para la Enseñanza de la Lengua Castellana en Educación

1 Artículo de investigación científica y tecnológica, resultado de la investigación "Tendencias de investigación en la Licenciatura en Educación Básica con énfasis en Humanidades y Lengua Castellana a nivel nacional desde el año 2011 a 2013", financiada por la Universidad Santo Tomás.

2 Licenciada en Español e Inglés, Áreas Mayores Universidad Pedagógica Nacional, especialista en Pedagogía de la Lengua Escrita, Universidad Santo Tomás, magíster en Psicología Comunitaria, Pontificia Universidad Javeriana. Docente investigadora principal Universidad Santo Tomás, Licenciatura en Educación Básica con énfasis en Humanidades y Lengua Castellana. Correo electrónico: anacanon@ ustadistancia.edu.co, analuciacanonmoreno@gmail.com, dirección de correspondencia: carrera 10 No. 72-50, teléfono de contacto: 5950000 ext. 2515, 2591, 2592.

3 Abogado Universidad de Nariño, magister en Literatura, Pontificia Universidad Javeriana, grado Magna Cum Laude. Docente co-investigador Universidad Autónoma de Colombia, Estudios Literarios. Correo electrónico: davidviveros@ustadistancia.edu.co, viverosgranja@gmail.com, dirección de correspondencia: calle 12 No. 4-31, teléfono de contacto: 3422736. 
Básica, están obligados a ajustarse a las exigencias del decreto 5443 del MEN, que reglamenta la denominación de los programas de preescolar, básica primaria, básica secundaria y educación media, agregando la especificación del área de trabajo del docente. El proyecto contempló programas de metodología a distancia y presencial, que obedecen a esta denominación. Como muestra, se trabajó con tres programas de universidades de Bogotá, incluido el de la Universidad Santo Tomás, y un programa de Medellín.

\section{Palabras clave:}

Educación básica, estado del arte, investigación formativa, tendencias de investigación, lenguaje y comunicación, lengua castellana.

\section{Research tendencies in basic education degree with emphasis in humanities and spanish language nationwide from 2011 to 2013}

\section{Abstract}

This paper presents the project "Trends in research in the Bachelor of Elementary Education with emphasis in Humanities and Spanish Language nationwide since 2011-2013", which arose from the need to recognize formative research for this program and contribute to the Bachelor transformation of the University Santo Tomas, considering the fact that the Bachelor programs for Spanish Language Teaching in Basic Education are required to comply with the requirements of Decree 5443 of MEN, that regulates the naming of programs of preschool, elementary, primary, lower secondary and secondary education, adding the specification of teachers' working area. The project included programs through distance and classroom methodology, which obey this designation. As an example, we worked with three programs of universities of Bogota, including St. Thomas University and one of Medellín. 


\section{Keywords:}

Basic education, formative research, research tendencies, language and communication, Spanish language, state of the art.

\section{Tendências de pesquisa na licenciatura em educação básica com ênfase em humanidades e língua espanhola no âmbito nacional desde o ano 2011 até 2013}

\section{Resumo}

Este artigo apresenta o projeto "Tendências em investigação no Bacharelado em Educação Básica com ênfase em Ciências Humanas e Língua Espanhola todo o país desde 2011-2013", que surgiu a partir da necessidade de reconhecer pesquisa formativa para este programa e contribuir para a Bachelor transformação da Universidade Santo Tomas, considerando o fato de que os programas de Licenciatura para Ensino da Língua Espanhola no Ensino Básico são obrigados a cumprir com os requisitos do Decreto 5443 de MEN, que regula a atribuição de nomes de programas de pré-escolar, elementar, fundamental, ensino médio e secundário inferior, acrescentando a especificação da área de trabalho dos professores. 0 projeto incluiu programas através de metodologia à distancia e sala de aula, que obedecem esta designação. Como exemplo, trabalhamos com três programas de universidades em Bogotá, incluindo Universidade Santo Tomas e um dos Medellín.

\section{Palavras-chave:}

A educação básica, o estado da arte, a pesquisa formativa, tendências de pesquisa, linguagem e comunicação, espanhol. 


\section{Introducción}

Las Licenciaturas en Educación Básica con énfasis en Humanidades y Lengua Castellana, surgen en Colombia a partir del Decreto No. 272 de 1998, artículos 23, 24, 25 de la Ley 115 de 1994, que pretende una formación de licenciados enfocados en un ciclo de educación y no solo en un área del conocimiento como tal. El Ministerio de Educación Nacional de Colombia (MEN) en su intención de garantizar mayor calidad en la formación de los maestros, emite el decreto 5443 de 2010, que reglamenta la nueva denominación de los programas de formación de docentes, la cual debe corresponder a los niveles de preescolar, básica primaria, básica secundaria y educación media, agregando la especificación del área de trabajo del docente.

Este proyecto reconoció algunas de las particularidades de los programas de formación de docentes de Educación Básica con énfasis en Humanidades y Lengua Castellana en las universidades del país; así como identificó los elementos que han caracterizado el desarrollo del componente investigativo en los mismos. Como antecedente investigativo, se tuvieron en cuenta los resultados de la investigación realizada el año inmediatamente anterior, dentro de este programa perteneciente a la Facultad de Educación de la Vicerrectoría de Universidad Abierta y a Distancia de la Universidad Santo Tomás. Una consulta inicial reconoció la existencia de nueve universidades que ofrecen el programa de Licenciatura en Educación Básica con énfasis en Humanidades y Lengua Castellana, de los cuales siete se dan bajo la metodología presencial, y dos a distancia.

Tabla 1. Resumen de las universidades que ofrecen el programa en el país

\begin{tabular}{l|c|c|c|c|c}
\hline Universidad & Presencial & $\begin{array}{c}\text { A } \\
\text { distancia }\end{array}$ & Bogotá & $\begin{array}{c}\text { En otras } \\
\text { ciudades }\end{array}$ & $\begin{array}{c}\text { Instituciones partici- } \\
\text { pantes directas del } \\
\text { proyecto }\end{array}$ \\
\hline $\begin{array}{l}\text { Pontificia Universidad } \\
\text { Javeriana }\end{array}$ & $X$ & $X$ & $X$ & $X$ \\
\hline $\begin{array}{l}\text { Corporación Universi- } \\
\text { taria Minuto de Dios }\end{array}$ & $X$ & $X$ & $X$ & $X$ & $X$ \\
\hline $\begin{array}{l}\text { Universidad Santo } \\
\text { Tomás }\end{array}$ & $X$ & & & $X$ & $X$ \\
\hline $\begin{array}{l}\text { San Buenaventura de } \\
\text { Medellín }\end{array}$ & $X$ & & $X$ \\
\hline
\end{tabular}




\begin{tabular}{l|c|c|c|c|c}
\hline Universidad & Presencial & $\begin{array}{c}A \\
\text { distancia }\end{array}$ & Bogotá & $\begin{array}{c}\text { En otras } \\
\text { ciudades }\end{array}$ & $\begin{array}{c}\text { Instituciones partici- } \\
\text { pantes directas del } \\
\text { proyecto }\end{array}$ \\
\hline $\begin{array}{l}\text { Universidad Distrital } \\
\text { Francisco José de } \\
\text { Caldas }\end{array}$ & $X$ & & $X$ & & \\
\hline $\begin{array}{l}\text { Universidad de } \\
\text { Córdoba }\end{array}$ & $X$ & & & $X$ & \\
\hline $\begin{array}{l}\text { Universidad de } \\
\text { Antioquia }\end{array}$ & $X$ & & & $X$ & \\
\hline $\begin{array}{l}\text { Tecnológico De } \\
\text { Antioquia }\end{array}$ & $X$ & & & $X$ & \\
\hline
\end{tabular}

Para el establecimiento de las tendencias de investigación formativa en el programa objeto de esta investigación, se adelantó la revisión de parte de 80 proyectos realizados por estudiantes de dos universidades de Bogotá y una de Medellín, lo cual permitió la formulación de cinco categorías temáticas, como una manera de establecer una tendencia en torno a los temas de investigación.

Tabla 2. Número de proyectos por categoría

\begin{tabular}{l|c|c}
\hline CATEGORÍA & NÚMERO DE PROYECTOS & \multirow{2}{*}{ TOTALIDAD } \\
\hline Paradigma y currículo & 13 proyectos & \\
\cline { 1 - 2 } Mediación docente & 32 proyectos & \multirow{2}{*}{80 proyectos } \\
\cline { 1 - 2 } Subjetividad y aprendizaje & 19 proyectos & \\
\cline { 1 - 2 } Gerencia educativa & 2 proyectos & \\
\hline Tecnología y aprendizaje & 14 proyectos & \\
\hline
\end{tabular}




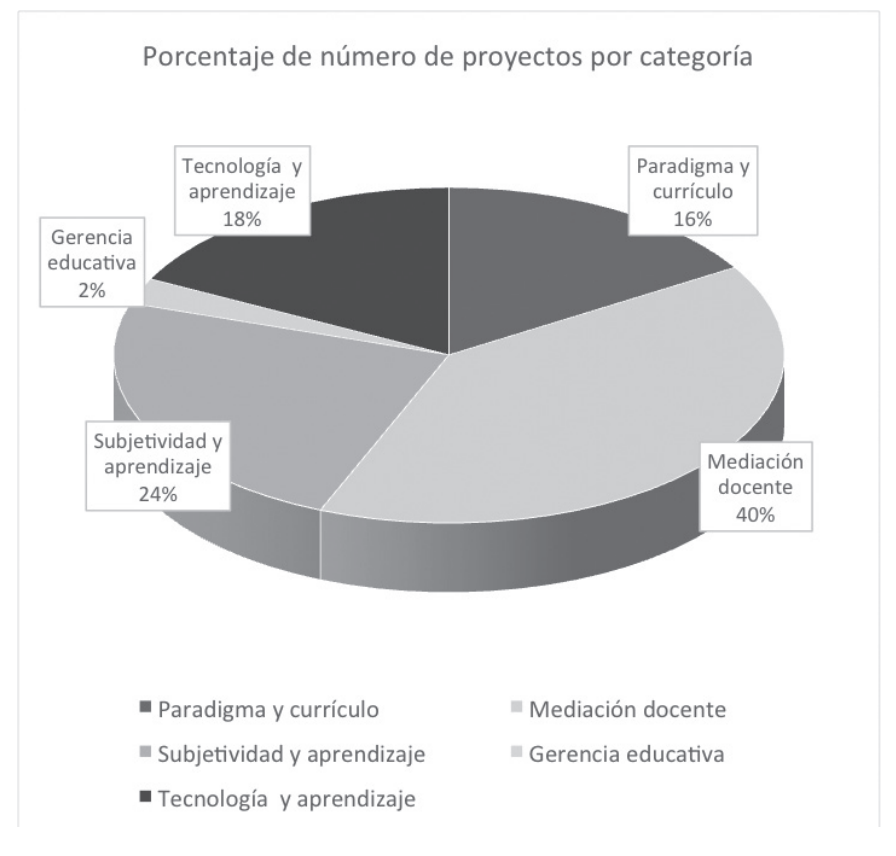

Figura 1. Porcentaje de número de proyectos por categoría

\section{Metodología}

La investigación formativa se considera investigación como tal porque siempre se plantea un problema y se intenta dar respuesta por medio de una teoría, de unos autores, a través de unas estrategias metodológicas y un enfoque que generalmente es de corte cualitativo. Cerda (2007) propone que la investigación formativa se vincule con la adquisición de una cultura investigativa, que permanezca en el docente en formación durante toda su vida en ejercicio de la docencia. Se entiende la investigación formativa como aquella que se relaciona con la formación pedagógica de los estudiantes en los programas de pregrado y de especialización.

El enfoque metodológico propuesto para el desarrollo de la investigación se enmarca epistemológicamente en la investigación cualitativa atendiendo al contexto sociocultural en el que la misma se desarrolla. La propuesta se generó en una lógica inductiva en el ejercicio de consultar qué y cómo se ha investigado a nivel 
formativo, en las licenciaturas de Educación Básica con énfasis en Humanidades y Lengua Castellana en cuatro universidades del país.

Una vez concluida la etapa de acopio, sistematización y análisis de la información, se establecieron resultados y conclusiones de la investigación.

El aspecto seleccionado para detectar las tendencias de investigación formativa de los graduandos fue la identificación de los volúmenes de problematización y de construcción de conocimiento. Entendiendo por volúmenes, fundamentalmente, el horizonte epistemológico y la información obtenida. Esto a partir de identificar cuáles son los campos de problematización y los temas recurrentes entre los estudiantes de pregrado para el desarrollo de sus proyectos de investigación.

Son tres los elementos observados y que constituyeron la estructura de las tendencias de investigación formativa:

1. Los problemas que se plantean, entendidos estos problemas como temas y preguntas de investigación.

2. La perspectiva teórica, desde la cual se formula la investigación, es decir, la manera como está construido teóricamente el problema o el marco conceptual que guía la búsqueda de respuestas de investigación.

3. La metodología, con la cual se construye el proyecto de investigación. Se trata de determinar el procedimiento para conseguir el conocimiento, o sea cuál es, en cada caso, la estrategia para responder las preguntas de la investigación.

La ruta metodológica fue la siguiente:

- Investigación de tipo documental, con el fin de ubicar fuentes que pudieran iluminar la realización de este proyecto y sentar las bases conceptuales del mismo.

- Rastreo y categorización de las investigaciones formativas, en los programas de Licenciatura en Educación Básica con énfasis en Humanidades y lengua Castellana de tres universidades de Bogotá y una de Medellín, tanto en documentos físicos como en repositorios virtuales.

- Entrevista a los directores de los programas participantes y a algunos de sus docentes, con el fin de profundizar en las particularidades de cada programa.

- Sistematización de la información atendiendo a las características generales de los programas de formación de docentes en Educación Básica con énfasis en Humanidades y Lengua Castellana en el país y a las particularidades de las 
universidades participantes en el proyecto frente al componente investigativo; así como a las especificidades de los proyectos consultados y dentro de ellos el establecimiento de cinco categorías temáticas, la pertinencia de las investigaciones realizadas, la clasificación de las preguntas de investigación y el enfoque metodológico de los proyectos revisados.

\section{Resultados}

El rastreamiento a las instituciones no participantes en el proyecto se realizó a través de sus dominios de Internet. Esta indagación permitió descubrir que nueve universidades ofrecen el programa bajo la misma denominación, de las cuales siete se dan bajo la metodología presencial, y dos a distancia. Siete de estos programas comprenden diez semestres de formación, uno nueve y uno ocho. La Universidad San Buenaventura de Medellín brinda el programa también en la modalidad semipresencial, los sábados, y su duración es de 12 semestres. En cuanto a los planes de estudio, en general todos atienden diversos campos de formación que incluyen áreas obligatorias y electivas; algunas, del campo de la pedagogía y otras del campo disciplinar. Frente a los programas analíticos revisados, en el caso de las disciplinas de investigación, se tuvieron en cuenta básicamente los objetivos y la metodología, y frente a las disciplinas de los otros campos de formación del programa, se atendió además, a los contenidos temáticos. En general, sus énfasis giran en torno a la comprensión significativa de procesos de la comunicación, la lengua y la literatura.

Tabla 3. Datos específicos por universidad basados en páginas web y entrevista personalizada

\begin{tabular}{l|l|l|l|l|l}
\hline \multicolumn{1}{c|}{ Institución } & $\begin{array}{c}\text { Código } \\
\text { SNIES }\end{array}$ & $\begin{array}{c}\text { Número de } \\
\text { créditos }\end{array}$ & $\begin{array}{c}\text { Duración en } \\
\text { semestres }\end{array}$ & Modalidad & Costo \\
\hline $\begin{array}{l}\text { Universidad } \\
\text { Santo Tomás }\end{array}$ & 12094 & 157 & 10 & Distancia & $\$ 1.818 .000$ \\
\hline $\begin{array}{l}\text { Pontificia } \\
\text { Universidad } \\
\text { Javeriana }\end{array}$ & 15442 & 170 & 10 & Distancia & $\$ 1.499 .000$ \\
\hline
\end{tabular}




\begin{tabular}{l|l|l|l|l|l}
\hline $\begin{array}{l}\text { Corporación Uni- } \\
\text { versitaria Minuto } \\
\text { de Dios }\end{array}$ & 12226 & 144 & 9 & Presencial & $\$ 1.710 .000$ \\
\hline $\begin{array}{l}\text { San Buenaven- } \\
\text { tura de Medellín }\end{array}$ & $\begin{array}{l}1717437 \\
0400050 \\
0111100\end{array}$ & 168 & $\begin{array}{l}10(12 \\
\text { sabatino })\end{array}$ & Presencial & \\
\hline $\begin{array}{l}\text { Universidad Dis- } \\
\text { trital Francisco } \\
\text { José de Caldas }\end{array}$ & 11348 & 173 & 10 & Presencial & $\begin{array}{l}\text { Atiende } \\
\text { criterios de } \\
\text { económico socio- } \\
\text { de colegio de } \\
\text { egreso. }\end{array}$ \\
\hline $\begin{array}{l}\text { Universidad de } \\
\text { Córdoba }\end{array}$ & 11942 & 10 & 10 & Presencial & \\
\hline $\begin{array}{l}\text { Universidad de } \\
\text { Antioquia }\end{array}$ & 01603 & 208 & 10 & Presencial & \\
\hline $\begin{array}{l}\text { Tecnológico de } \\
\text { Antioquia }\end{array}$ & 10667 & 180 & 10 & Presencial & $\$ 770.000$ \\
\hline $\begin{array}{l}\text { Universidad } \\
\text { Surcolombiana }\end{array}$ & 0103072 & 119 & 8 & Presencial & \\
\hline
\end{tabular}

\begin{tabular}{l|l|l|l}
\hline \multicolumn{1}{c|}{ Institución } & \multicolumn{1}{|c|}{ Énfasis } & $\begin{array}{l}\text { Requisito en lengua } \\
\text { extranjera }\end{array}$ & \multicolumn{1}{c}{ Opciones de grado } \\
\hline & $\begin{array}{l}\text { Significación } \\
\text { en la lengua } \\
\text { castellana: } \\
\text { significa- } \\
\text { ción en la } \\
\text { literatura. }\end{array}$ & $\begin{array}{l}\text { Cuatro niveles de } \\
\text { inglés cursados } \\
\text { en la universi- } \\
\text { dad o prueba de } \\
\text { suficiencia. }\end{array}$ & $\begin{array}{l}\text { - Proyecto de investigación. } \\
\text { Santo Tomablicación de un artículo. }\end{array}$ \\
& $\begin{array}{l}\text { - Pealización de una ponencia. } \\
\text { semillero. }\end{array}$ \\
\hline
\end{tabular}




\begin{tabular}{|c|c|c|c|}
\hline Institución & Énfasis & $\begin{array}{c}\text { Requisito en lengua } \\
\text { extranjera }\end{array}$ & Opciones de grado \\
\hline $\begin{array}{l}\text { Pontificia } \\
\text { Universidad } \\
\text { Javeriana }\end{array}$ & $\begin{array}{l}\text { Lenguaje: } \\
\text { reflexión } \\
\text { pedagógica. }\end{array}$ & $\begin{array}{l}\text { Nivel A2 en inglés } \\
\text { del MCE (se tiene } \\
\text { la intención de } \\
\text { empezar a exigir el } \\
\text { nivel B1). }\end{array}$ & $\begin{array}{l}\text { El trabajo de grado como ejerci- } \\
\text { cio de investigación educativa, } \\
\text { alrededor de la problematización } \\
\text { en el aula }\end{array}$ \\
\hline $\begin{array}{l}\text { Corporación } \\
\text { Universitaria } \\
\text { Minuto de } \\
\text { Dios }\end{array}$ & & $\begin{array}{l}\text { Tres niveles de } \\
\text { inglés. }\end{array}$ & $\begin{array}{l}\text { - Monografía aprobada y } \\
\text { - Custentada. } \\
\text { - internacional. } \\
\text { - Proyecto de grado. } \\
\text { - Diplomado a través de la } \\
\text { Especialización en Procesos } \\
\text { Lectores. }\end{array}$ \\
\hline $\begin{array}{l}\text { San Buena- } \\
\text { ventura de } \\
\text { Medellín }\end{array}$ & $\begin{array}{l}\text { Pensamiento } \\
\text { y lenguaje. }\end{array}$ & $\begin{array}{l}\text { Dos cursos de inglés } \\
\text { que se pagan aparte } \\
\text { de la matrícula, } \\
\text { deben certificar el } \\
\text { nivel B1 del MCE. }\end{array}$ & $\begin{array}{l}\text { - Trabajo de grado con aplica- } \\
\text { ción en el aula. } \\
\text { - Realización de monografía. }\end{array}$ \\
\hline $\begin{array}{l}\text { Universidad } \\
\text { Distrital Fran- } \\
\text { cisco José de } \\
\text { Caldas }\end{array}$ & $\begin{array}{l}\text { Lectura y } \\
\text { escritura. }\end{array}$ & $\begin{array}{l}\text { No se encontró } \\
\text { información en el } \\
\text { dominio de Internet. }\end{array}$ & $\begin{array}{l}\text { No se encontró información en el } \\
\text { dominio de Internet. }\end{array}$ \\
\hline $\begin{array}{l}\text { Universidad } \\
\text { de Córdoba }\end{array}$ & $\begin{array}{l}\text { Lingüística y } \\
\text { literatura en } \\
\text { contexto. }\end{array}$ & 4 niveles de inglés. & $\begin{array}{l}\text { No se encontró información en el } \\
\text { dominio de Internet. }\end{array}$ \\
\hline $\begin{array}{l}\text { Universidad } \\
\text { de Antioquia }\end{array}$ & $\begin{array}{l}\text { Procesos } \\
\text { comunicati- } \\
\text { vos lengua y } \\
\text { literatura. }\end{array}$ & $\begin{array}{l}\text { No se encontró } \\
\text { información en el } \\
\text { dominio de Internet. }\end{array}$ & $\begin{array}{l}\text { No se encontró información en el } \\
\text { dominio de Internet. }\end{array}$ \\
\hline
\end{tabular}

Entre las especificidades de los programas participantes, se encontró que:

La Universidad Santo Tomás reconoce de manera especial el valor de la metodología a distancia (tradicional) porque es consciente de los diferentes problemas de 
la educación superior en las regiones más apartadas del país, en donde a través de la metodología y el tipo de presencia que hace la universidad, se visibiliza una alternativa para democratizar la educación y hacer de ella un recurso flexible, que permite atender las necesidades de formación y capacitación de profesionales de la educación" (Documento Maestro para el registro calificado, 2010).

Basa su propuesta de plan de estudios en cuatro campos de formación: pedagógico, humanístico, investigativo y específico. Brinda la oportunidad de dos líneas de profundización en las que se sustenta además, el proyecto de grado, una sobre la significación de la Lengua Castellana y otra sobre la significación de la Literatura. La investigación es direccionada desde el enfoque Crítico Social Abierto, que guarda una estrecha relación con el curriculum problematizador. El centro de esta relación es el estudiante. Esta articulación vela porque se armonicen las diversas dimensiones de los educandos. Busca un balance entre lo cognitivo y lo afectivo, entre lo vivencial y lo racional, entre lo colectivo y lo individual.

La Corporación Universitaria Minuto de Dios propende por la formación de un maestro innovador, investigador desde la praxis entendida como una práctica ética. Los programas de la Facultad de Educación intentan formar maestros con un gran énfasis en su saber disciplinar. El enfoque es el praxeológico propuesto por el profesor Carlos Juliao Vargas, en el que impera la vivencia del sentido de la equidad y que comprende cuatro etapas: ver, juzgar, actuar y generar revolución creativa. El Proyecto Educativo Institucional se basa en la obra del padre Rafael García Herreros, que incluye el carisma y los principios eudistas. Se plantea la opción de "Educación para todos", no hay filtros de selección para el ingreso. Desde lo disciplinar, el programa de Básica en Lengua Castellana otorga una formación amplia que permite la realización de actividades, como la traducción y la corrección de textos. Igualmente fortalece la formación pedagógica que busca una integración lo más real posible con el aula.

La Pontificia Universidad Javeriana desarrolla su programa en la modalidad a distancia y comprende también cuatro campos del conocimiento relacionados con pedagogía, lenguaje, investigación y humanidades. Posee dos énfasis: lenguaje y contexto; lenguaje y escuela. El Plan de estudios presenta un núcleo de formación fundamental, que ofrece unas herramientas para pensar la pedagogía como un "saber fundante" y pensar la investigación como el espacio donde se produce el saber pedagógico desde el lenguaje. Entiende la investigación como un eje transversal y a lo largo de la carrera se dan algunos ejercicios investigativos, siendo el trabajo 
de grado el que exige mayor dedicación. Está conformado por tres seminarios: uno de problematización; otro tiene que ver con el lenguaje y un último con las tecnologías de investigación aplicadas. Cuando los estudiantes llegan a séptimo semestre escogen en cuál línea les gustaría hacer la investigación e inician la etapa de problematización. En octavo semestre, pasan a un nivel de documentación y en ese momento se les ofrecen herramientas metodológicas para la elaboración del marco teórico e instrumentos con los que desarrollarán la metodología para la investigación, el trabajo de campo y la recolección de la información.

La Universidad San Buenaventura de Medellín brinda su formación a partir de proyectos pedagógicos y seminarios específicos que se concretan en cátedras de pedagogía estudiadas durante todos los semestres. Igualmente, se da un fuerte énfasis en formación humana, componente que se trabaja en los primeros cinco semestres. El trabajo de grado se realiza en los dos últimos semestres, y el proyecto pedagógico se asume durante todos los semestres. A partir del segundo semestre de 2012, aprovechando la renovación del registro calificado, el programa cambió su denominación y enfoque de Licenciatura en Educación Básica con énfasis en Humanidades y Lengua Castellana a Licenciatura en Lengua Castellana, porque el primero poseía muchas generalidades sobre el saber disciplinar de la Lengua Castellana; pero hacía poco énfasis en la lengua como objeto de estudio en la escuela; otra razón fue el poco espacio que se otorgaba entonces a la Literatura. La nueva denominación resulta más acorde con las convocatorias laborales realizadas desde el sector oficial; y esta se ha convertido en una oportunidad para los estudiantes, toda vez que les ha brindado un panorama más amplio porque el título anterior restringía su posibilidad de desempeño, puesto que aunque la licenciatura habilitaba a sus egresados para ser docentes entre primero y noveno grado de enseñanza básica, se generó un imaginario de que se estaba ofertando un programa para docentes de básica primaria. Actualmente, la investigación se ve en todos los 10 semestres, aunque esta no se haga explícita en los nombres de las asignaturas. La misma se desarrolla por medio de ciclos que comprenden la reflexión que articula al sujeto con la pedagogía, entendida como proyecto de vida; la transformación socioeducativa, ciclo que consiste en un acercamiento a la institución educativa; el proyecto pedagógico, que se propone trasladar la investigación a distintos escenarios sociales y culturales; los contextos y los métodos de aprendizaje que trabajan con la didáctica aplicada a la enseñanza-aprendizaje con niños y niñas especiales.

Frente a los proyectos consultados, algunos no evidencian una relación directa con el área de Lengua Castellana, y más bien se enfocan en otras temáticas, 
que incluso en algunas ocasiones parecen no surgir directamente del trabajo de aula. A partir de tales desplazamientos se puede resaltar que hay una tendencia a relegar la importancia de la enseñanza de la Lengua Castellana como propósito fundamental y que, entonces, se le otorga a esta un papel satélite y auxiliar de otros propósitos, que pueden ser pedagógicamente válidos; pero que descentran la enseñanza-aprendizaje de la lengua hacia otras disciplinas.

Tabla 4. Clasificación de proyectos de investigación en pertinentes y no pertinentes con la enseñanza-aprendizaje de la Lengua Castellana, atendiendo a su denominación (UNIMINUTO, PUJ, USB)

\begin{tabular}{|c|c|}
\hline PER & \\
\hline $\begin{array}{l}\text { Renovación malla curricular plan de área Len- } \\
\text { gua Castellana. } \\
\text { Desarrollo de la competencia interpretativa } \\
\text { a través del libro álbum para grado tercero de } \\
\text { primaria. } \\
\text { Reestructuración del Plan de estudios de Len- } \\
\text { gua Castellana del Colegio Colombo Italiano } \\
\text { Michelangelo. } \\
\text { Enfoques y metodologías en la enseñanza de la } \\
\text { gramática de la Lengua Castellana en la Insti- } \\
\text { tución Educativa Normal Superior de Envigado. } \\
\text { Relación entre las imágenes y el texto de los } \\
\text { cuentos infantiles Eloísa y los bichos y Camino } \\
\text { a casa del autor Jairo Buitrago. } \\
\text { Las isotopías de ausencia y presencia en el } \\
\text { cuento El crimen (2006) de Efraím Medina Re- } \\
\text { yes, mediante el concepto de visión de mundo. } \\
\text { Análisis semiótico de la red social Facebook, } \\
\text { perfil de vida. } \\
\text { Dime qué ves y te diré qué escribes. } \\
\text { Recurso virtual de aprendizaje sobre la historia } \\
\text { de la lengua española. }\end{array}$ & $\begin{array}{l}\text { comprensión de textos. } \\
\text { Los valores en la formación humana de los estu- } \\
\text { diantes de cuarto del Colegio Villa Esther. } \\
\text { Escuela y danza una forma creativa para lograr } \\
\text { la humanización. } \\
\text { Discurso y pedagogía: análisis de las propuestas } \\
\text { pedagógicas de Jaime Garzón, a propósito de la } \\
\text { educación en Colombia. } \\
\text { El maravilloso mundo de los cuentos de hadas. } \\
\text { Enrique Serrano y Fernando Vallejo: dos concep- } \\
\text { ciones opuestas de hombre. } \\
\text { Visión del mundo de la novela: El olvido que se- } \\
\text { remos de Héctor Abad Faciolince. } \\
\text { La televisión, un espacio para la construcción de } \\
\text { modelos de héroe. } \\
\text { Metodología del cine formativo: icuál es la pre- } \\
\text { sencia del cine en los programas de Licenciatura } \\
\text { en Humanidades en algunas Universidades de } \\
\text { Bogotá-Colombia? } \\
\text { Informar, una estrategia para enseñar. } \\
\text { Desarrollo de la argumentación haciendo uso de } \\
\text { filosofía para niños. }\end{array}$ \\
\hline
\end{tabular}




\begin{tabular}{|c|c|}
\hline PERT & IO PERTINENTE \\
\hline $\begin{array}{l}\text { Sin televisión y sin destreza los niños pierden la } \\
\text { cabeza. Los Simpson: una guía para el ejercicio } \\
\text { de la escritura. } \\
\text { Estimula tus sentidos: lee y escribe. } \\
\text { Es el momento de hablar, leer, escuchar y } \\
\text { escribir. } \\
\text { La lectura en voz alta del cuento y la fábula, una } \\
\text { entrada al conocimiento. } \\
\text { Sistematización de los proyectos de prácticas } \\
\text { profesionales correspondientes a la Licenciatura } \\
\text { de Humanidades y Lengua } \\
\text { Castellana (2005-2011). } \\
\text { La integración de los juegos pedagógicos virtua- } \\
\text { les en el proceso de comprensión lectora. } \\
\text { La formación inicial de la escritura a través de } \\
\text { un libro de multimedia. } \\
\text { Análisis semiótico de los lenguajes de un grupo } \\
\text { de jóvenes de Facebook. } \\
\text { Invitación a descubrir el mundo a través de la } \\
\text { lectura. Estrategias de promoción y animación } \\
\text { a la lectura enfocada en la comprensión lectora } \\
\text { en grado tercero. } \\
\text { Orientación pedagógica y didáctica, para for- } \\
\text { talecer la competencia textual de menores en } \\
\text { estado de vulnerabilidad. } \\
\text { El discurso oral explicativo en el ámbito de la } \\
\text { clase. } \\
\text { El cómic como estrategia didáctica para poten- } \\
\text { ciar la competencia comunicativa en los estu- } \\
\text { diantes del grado quinto de la Institución Edu- } \\
\text { cativa Privada Campo Hermoso. } \\
\text { Desarrollo de competencias referidas a la com- interpretación de textos mediante el } \\
\text { cébora Arango Pérez. }\end{array}$ & $\begin{array}{l}\text { Postura crítica frente a la sociedad colombiana } \\
\text { en las obras Flor del fango de José María Vargas } \\
\text { Vila y El desbarrancadero de Fernando Vallejo. } \\
\text { El insulto como medio de expresión de los jóve- } \\
\text { nes en Bogotá. } \\
\text { Desde la literatura hasta la ideología en los } \\
\text { cuentos del padre Rafael García Herreros. } \\
\text { Las prácticas sociales en los juegos tradicionales } \\
\text { populares. } \\
\text { El uso del blog como estrategia de fortalecimien- } \\
\text { to del sentido de pertenencia. } \\
\text { Condiciones de posibilidad para el diseño de un } \\
\text { museo pedagógico para la Universidad de San } \\
\text { Buenaventura de Medellín. } \\
\text { Impacto del programa computadores para edu- } \\
\text { car en los procesos de incorporación de las TIC } \\
\text { en la Institución Ramón Alvarado Sánchez (El } \\
\text { Paraíso, Garzón). } \\
\text { Diagnóstico del uso de las TIC en la básica y media } \\
\text { del Colegio Jesús María de la ciudad de Medellín. } \\
\text { Currículo oculto, resistencias y lenguaje en es- } \\
\text { tudiantes de bachillerato del Liceo Femenino } \\
\text { Mercedes Nariño. } \\
\text { ¿Las prácticas de educación utilizadas por los } \\
\text { docentes en los procesos formativos contribuyen } \\
\text { al desarrollo del pensamiento crítico de los } \\
\text { alumnos de sexto del Colegio Nuestra Señora de } \\
\text { Fátima de Popayán? } \\
\text { Una mirada crítica a las concepciones de amor, } \\
\text { diálogo y praxis en las prácticas pedagógicas en } \\
\text { un colegio religioso. } \\
\text { Las prácticas pedagógicas en un colegio distrital } \\
\text { de Bogotá, illevan al pensamiento crítico y a la } \\
\text { autonomía? }\end{array}$ \\
\hline
\end{tabular}




\begin{tabular}{l|l}
\hline PERTINENTE & NO PERTINENTE \\
\hline Propuesta club de lectura RELATA. Propuesta & Análisis crítico de las prácticas pedagógicas en \\
para el fortalecimiento del hábito lector de los & la enseñanza de las Ciencias Sociales en el Ins- \\
estudiantes del programa LBHL de la Facultad & titución San Juan de Dios de Bogotá. \\
de Educación de la Corporación Universitaria & La implementación de la lúdica en el proceso de \\
Minuto de Dios. & enseñanza y aprendizaje de los educandos. \\
La influencia del discurso docente del lenguaje & Concepto de ser humano en las prácticas peda- \\
en el proceso lector. & $\begin{array}{l}\text { gógicas del Colegio Sagrado Corazón de Jesús de } \\
\text { La ortografía en los primeros años de escolaridad. } \\
\text { Bucaramanga, de décimo y once. } \\
\text { El taller como búsqueda de la significación. } \\
\text { Ciudadanos críticos leyendo en contexto. Diseño } \\
\text { de una propuesta didáctica enfocada en potenciar } \\
\text { la formación ciudadana desde la lectura crítica. } \\
\text { La reconstrucción de identidad de un grupo de } \\
\text { desplazados y las herramientas virtuales. } \\
\text { Incidencia de las conductas sociales y familiares } \\
\text { en la construcción del proceso de lecto-escritura } \\
\text { en niños y niñas. }\end{array}$ \\
\hline
\end{tabular}

La Tabla 2. Número de proyectos por categoría, evidencia que sobresale la categoría de mediación docente, que comprende temas referidos a la didáctica de la Lengua Castellana, las prácticas educativas, el campo del lenguaje y la gramática. Esta categoría pone el acento en que los docentes son mediadores de los procesos de aprendizaje; en que no son ellos los generadores del aprendizaje o los determinadores, sino que constituyen una instancia que acompaña el proceso y dan herramientas para que los estudiantes vayan generando sus conocimientos constructivamente y a través de procesos propios. La categoría de tecnología y aprendizaje constituye un tema vigente y ocupa una tendencia mayor en los proyectos revisados. Se encuentra una orientación a proyectos en los que se hace referencia al uso lúdico y creativo de las mediaciones tecnológicas, y otra en la que se ofrece una lectura crítica del uso de las TIC. La categoría de paradigma y currículo incluye los temas de construcción del currículo, paradigmas (valores, visión de mundo) y desarrollo de aspectos subjetivos en la persona, tiene que ver con la filosofía y la axiología de la educación. En este acápite se intenta rescatar el tema de para qué es la educación, en vista de que de alguna manera se ha convertido en un asunto técnico. También se intenta resolver qué es lo pedagógico, cuáles son los modelos de la enseñanza que más participan en el aula y qué tan apropiados resultan. En la categoría de subjetividad y aprendizaje se observa una tendencia a proyectos basados en grupos humanos con algunas peculiaridades importantes tales como el 
desplazamiento, la población indígena, la comunicación entre la población joven y la práctica social frente a los juegos tradicionales. También hace planteamientos sobre cómo participa la constelación de fenómenos subjetivos en la generación de procesos de aprendizaje y cómo el aprendizaje está vinculado con temáticas como la biografía, las relaciones familiares, clánicas y comunitarias. La categoría de gerencia educativa, tiene que ver obviamente con planes, proyectos y políticas de administración educativa. Resultan escasas las investigaciones en este campo.

Tabla 5. Clasificación por categoría temática general de los proyectos revisados

\begin{tabular}{|c|c|c|c|}
\hline CATEGORÍA & $\begin{array}{l}\text { UNIVERSIDAD MINUTO } \\
\text { DE DIOS }\end{array}$ & $\begin{array}{l}\text { PONTIFICIA UNIVERSI- } \\
\text { DAD JAVERIANA }\end{array}$ & $\begin{array}{l}\text { UNIVERSIDAD SAN } \\
\text { BUENAVENTURA DE } \\
\text { MEDELLIIN }\end{array}$ \\
\hline $\begin{array}{l}\text { PARA- } \\
\text { DIGMA Y } \\
\text { CURRÍCULO }\end{array}$ & $\begin{array}{l}\text { La enseñanza de los valo- } \\
\text { res morales mediante la } \\
\text { comprensión de textos. } \\
\text { Renovación malla curri- } \\
\text { cular plan de área Lengua } \\
\text { Castellana. } \\
\text { Reestructuración del } \\
\text { Plan de estudios de } \\
\text { Lengua Castellana del } \\
\text { Colegio Colombo Italiano } \\
\text { Michelangelo. } \\
\text { Enrique Serrano y Fernan- } \\
\text { do Vallejo: dos concepcio- } \\
\text { nes opuestas del hombre. }\end{array}$ & $\begin{array}{l}\text { Escuela y danza, una } \\
\text { forma creativa para lograr } \\
\text { la humanización. } \\
\text { Los valores en la for- } \\
\text { mación humana de los } \\
\text { estudiantes de cuarto del } \\
\text { Colegio Villa Esther. } \\
\text { Análisis de experien- } \\
\text { cias educativas en los } \\
\text { movimientos sociales } \\
\text { indígenas del Cauca en } \\
\text { Colombia y Ecuador, un } \\
\text { estudio de casos. } \\
\text { Evaluación de la lectura y } \\
\text { la escritura. }\end{array}$ & $\begin{array}{l}\text { Enfoques y metodologías } \\
\text { en la enseñanza de la } \\
\text { gramática de la lengua } \\
\text { castellana en la Institu- } \\
\text { ción Educativa Normal } \\
\text { Superior de Envigado. }\end{array}$ \\
\hline $\begin{array}{l}\text { TECNO- } \\
\text { LOGÍA Y } \\
\text { APRENDI- } \\
\text { ZAJE }\end{array}$ & $\begin{array}{l}\text { Análisis semiótico de la } \\
\text { red social Facebook, perfil } \\
\text { de vida. } \\
\text { La televisión, un espacio } \\
\text { para la construcción de } \\
\text { modelos de héroe. } \\
\text { Recurso virtual de apren- } \\
\text { dizaje sobre la historia de } \\
\text { la lengua española. }\end{array}$ & $\begin{array}{l}\text { La formación inicial de la } \\
\text { escritura a través de un } \\
\text { libro de multimedia. } \\
\text { El uso del blog como } \\
\text { estrategia de fortaleci- } \\
\text { miento del sentido de } \\
\text { pertenencia. }\end{array}$ & $\begin{array}{l}\text { Diagnóstico del uso de las } \\
\text { TIC en la básica y media } \\
\text { del Colegio Jesús María } \\
\text { de la ciudad de Medellín. } \\
\text { Condiciones de posibili- } \\
\text { dad para el diseño de un } \\
\text { museo pedagógico para la } \\
\text { Universidad de San Bue- } \\
\text { naventura de Medellín. }\end{array}$ \\
\hline
\end{tabular}




\begin{tabular}{|c|c|c|c|}
\hline CATEGORÍA & $\begin{array}{l}\text { UNIVERSIDAD MINUTO } \\
\text { DE DIOS }\end{array}$ & $\begin{array}{l}\text { PONTIFICIA UNIVERSI- } \\
\text { DAD JAVERIANA }\end{array}$ & $\begin{array}{l}\text { UNIVERSIDAD SAN } \\
\text { BUENAVENTURA DE } \\
\text { MEDELLÍN }\end{array}$ \\
\hline $\begin{array}{l}\text { TECNO- } \\
\text { LOGÍA Y } \\
\text { APRENDI- } \\
\text { ZAJE }\end{array}$ & $\begin{array}{l}\text { Sin televisión y sin des- } \\
\text { treza los niños pierden la } \\
\text { cabeza. Los Simpson: una } \\
\text { guía para el ejercicio de } \\
\text { la escritura. }\end{array}$ & $\begin{array}{l}\text { Impacto del programa } \\
\text { computadores para } \\
\text { educar en los procesos de } \\
\text { incorporación de las TIC } \\
\text { en la Institución Ramón } \\
\text { Alvarado Sánchez (EI } \\
\text { Paraíso, Garzón). }\end{array}$ & $\begin{array}{l}\text { La integración de los } \\
\text { juegos pedagógicos } \\
\text { virtuales en el proceso de } \\
\text { comprensión lectora. }\end{array}$ \\
\hline $\begin{array}{l}\text { MEDIACIÓN } \\
\text { DOCENTE }\end{array}$ & $\begin{array}{l}\text { La lectura en voz alta del } \\
\text { cuento y la fábula, una } \\
\text { entrada al conocimiento. } \\
\text { Desarrollo de la argumen- } \\
\text { tación haciendo uso de } \\
\text { filosofía para niños. } \\
\text { Invitación a descubrir } \\
\text { el mundo a través de la } \\
\text { lectura. Estrategias de } \\
\text { promoción y animación a } \\
\text { la lectura enfocada en la } \\
\text { comprensión lectora en } \\
\text { grado tercero. } \\
\text { Orientación pedagógica y } \\
\text { didáctica, para fortalecer } \\
\text { la competencia textual } \\
\text { de menores en estado de } \\
\text { vulnerabilidad. }\end{array}$ & $\begin{array}{l}\text { El discurso oral explicativo } \\
\text { en el ámbito de la clase. } \\
\text { Currículo oculto, resis- } \\
\text { tencias y lenguaje en } \\
\text { estudiantes de bachille- } \\
\text { rato del Liceo Femenino } \\
\text { Mercedes Nariño. } \\
\text { Prácticas de enseñanza } \\
\text { de la ortografía en los gra- } \\
\text { dos tercero y quinto. } \\
\text { ¿Las prácticas de educación } \\
\text { utilizadas por los docentes } \\
\text { en los procesos formativos } \\
\text { contribuyen al desarrollo } \\
\text { del pensamiento crítico de } \\
\text { los alumnos de sexto del } \\
\text { Colegio Nuestra Señora de } \\
\text { Fátima de Popayán? }\end{array}$ & $\begin{array}{l}\text { El taller como búsqueda } \\
\text { de la significación. }\end{array}$ \\
\hline $\begin{array}{l}\text { SUBJETI- } \\
\text { VIDAD Y } \\
\text { APRENDI- } \\
\text { ZAJE }\end{array}$ & $\begin{array}{l}\text { Postura crítica frente a la } \\
\text { sociedad colombiana en } \\
\text { las obras Flor del fango } \\
\text { de José María Vargas Vila } \\
\text { y El desbarrancadero de } \\
\text { Fernando Vallejo. } \\
\text { El insulto como medio de } \\
\text { expresión de los jóvenes } \\
\text { en Bogotá. }\end{array}$ & $\begin{array}{l}\text { Ciudadanos críticos leyendo } \\
\text { en contexto: diseño de } \\
\text { una propuesta didáctica } \\
\text { enfocada en potenciar la } \\
\text { formación ciudadana desde } \\
\text { la lectura crítica. } \\
\text { Incidencia de las conduc- } \\
\text { tas sociales y familiares } \\
\text { en la construcción del } \\
\text { proceso de lecto-escritura } \\
\text { en niños y niñas. }\end{array}$ & $\begin{array}{l}\text { El universo estético juve- } \\
\text { nil y su contribución a los } \\
\text { procesos de enseñanza } \\
\text { de la educación artística } \\
\text { y cultural: una propuesta } \\
\text { metodológica. }\end{array}$ \\
\hline
\end{tabular}




\begin{tabular}{|c|c|c|c|}
\hline $\begin{array}{l}\text { SUBJETI- } \\
\text { VIDAD Y } \\
\text { APRENDI- } \\
\text { ZAJE }\end{array}$ & $\begin{array}{l}\text { Desde la literatura } \\
\text { hasta la ideología en los } \\
\text { cuentos del Padre Rafael } \\
\text { García Herreros. } \\
\text { Las prácticas sociales en } \\
\text { los juegos tradicionales } \\
\text { populares. }\end{array}$ & $\begin{array}{l}\text { Comunidades de práctica } \\
\text { como generadoras de } \\
\text { pensamiento crítico. } \\
\text { Rescate del lector escritor } \\
\text { competente a través de la } \\
\text { cultura Wayúu. }\end{array}$ & $\begin{array}{l}\text { Análisis de los factores de } \\
\text { protección a la infancia } \\
\text { de algunas familias en } \\
\text { situación de vulnerabi- } \\
\text { lidad, de la institución } \\
\text { educativa Luis Carlos } \\
\text { Galán Sarmiento del } \\
\text { municipio de Itagüí. }\end{array}$ \\
\hline $\begin{array}{l}\text { GERENCIA } \\
\text { EDUCATIVA }\end{array}$ & & & $\begin{array}{l}\text { Control interno para las } \\
\text { universidades privadas. } \\
\text { Gerenciamiento de un } \\
\text { currículo para la forma- } \\
\text { ción de competencias } \\
\text { ciudadanas. }\end{array}$ \\
\hline
\end{tabular}

Las investigaciones formativas adelantadas con enfoque cualitativo se podrían clasificar en tres grandes líneas metodológicas, atendiendo a que los acercamientos investigativos se complementan con la aplicación de la intervención en la que se construyen herramientas que facilitan el diálogo, los espacios de reflexión y especialmente la apuesta por un tipo de cambio, de mejoramiento, cualificación y discusión en alguna de las metodologías de abordaje de la Lengua Castellana. Estas tres grandes líneas son, a saber:

4. Las que contemplan instrumentos de tipo lúdico, narrativo y simbólico, que permitieron, por inferencia interpretativa, hermenéutica, analítica, acceder a los ámbitos de estudio. Los instrumentos utilizados fueron: historias de vida, dinámicas grupales virtuales y factuales, alusiones de sentido, juegos, ejercicio de construcción narrativa y diferentes técnicas de observación.

5. Las que asumen métodos interrogativos que permiten recoger opiniones directas sobre los aspectos interrogados en las preguntas de investigación previamente formuladas. Los instrumentos encontrados en este caso son: encuestas y entrevistas semiestructuradas.

6. Las que se relacionan con proyectos de intervención, especialmente orientados hacia el campo pedagógico, didáctico y curricular.

La perspectiva ética y de sentido en la investigación formativa en las universidades participantes evidencia, a partir de las temáticas y de las preguntas de investigación, una preocupación por responder a la realidad socio-escolar, siendo 
de resaltar el reconocimiento de las características de las diferentes realidades institucionales, sociales, familiares, generacionales, étnicas, de género, tomadas en cuenta en los enfoques de investigación formativa; la valoración del conocimiento previo de los diferentes actores escolares, en términos de sus historias de vida, de sus pautas culturales, de sus desarrollos cognitivos y de la dinámica institucional; la recuperación de la capacidad de contar, narrar y compartir vivencias como experiencias significativas utilizables en el proceso de aprendizaje; el diseño creativo de la lúdica virtual y factual, como pedagogía y método de investigación, arrojando resultados muy importantes y mostrando caminos nuevos en el quehacer pedagógico; el énfasis en recuperar y aprender de la propia experiencia del docente a partir de su práctica pedagógica auto-cuestionada; la valoración de la experiencia previa, la inclusión de la actividad lúdico-artística, como instrumento formativo, que contribuye a develar, redescubrir y reinterpretar situaciones que no son fácilmente percibidas por los instrumentos cognitivos racionales; la aplicación inmediata del nuevo saber con el fin de convertirlo en guía para la acción, que es el caso de la investigación-intervención; la posibilidad de sistematizar la experiencia de cada participante durante el proceso pedagógico, más allá de lo que aporten como tal las conclusiones de la investigación.

Desde la perspectiva de las preguntas predominan las correspondientes al enfoque estratégico, es decir al de las investigaciones orientadas a generar resultados, que son investigaciones prácticas institucionales o administrativas, en las que se presuponen estrategias para obtener un resultado. El hecho de que las preguntas estratégicas se den en mayor número que las analíticas (que serían las preguntas propiamente de investigación), revelaría que se está dando una preocupación por la práctica, por la acción docente o pedagógica, es decir que, de algún modo, se está dando una predominancia del oficio docente sobre el de investigador. Se podría intentar un cuestionamiento en el sentido de que en las universidades participantes de este proyecto, no se están gestando docentes investigadores; sino cuadros de docentes profesionales, lo cual no está mal; pero definitivamente tendría que entrar a favorecerse también una perspectiva al mismo nivel en investigación. 
Tabla 6. Número de preguntas según el enfoque y categoría

\begin{tabular}{|c|c|c|}
\hline $\begin{array}{l}\text { Enfoque de la } \\
\text { pregunta }\end{array}$ & Número de preguntas según el enfoque & Categoría \\
\hline \multirow{4}{*}{ Estratégico } & 1 & Paradigma y currículo \\
\hline & 4 & Tecnología y aprendizaje \\
\hline & 10 & Mediación docente \\
\hline & 1 & Subjetividad y aprendizaje \\
\hline Total & 16 preguntas de enfoque estratégico & \\
\hline \multirow{3}{*}{ Exploratorio } & 1 & Paradigma y currículo \\
\hline & 1 & Tecnología y aprendizaje \\
\hline & 1 & Mediación docente \\
\hline Total & 3 preguntas de enfoque exploratorio & \\
\hline \multirow{4}{*}{ Analítico } & 5 & Paradigma y currículo \\
\hline & 2 & Tecnología y aprendizaje \\
\hline & 4 & Mediación docente \\
\hline & 3 & Subjetividad y aprendizaje \\
\hline Total & 14 preguntas de enfoque analítico & \\
\hline Reflexivo & 1 & Paradigma y currículo \\
\hline Total & 1 pregunta de enfoque reflexivo & \\
\hline
\end{tabular}




\section{Número de preguntas según el enfoque en las investigaciones estudiadas}

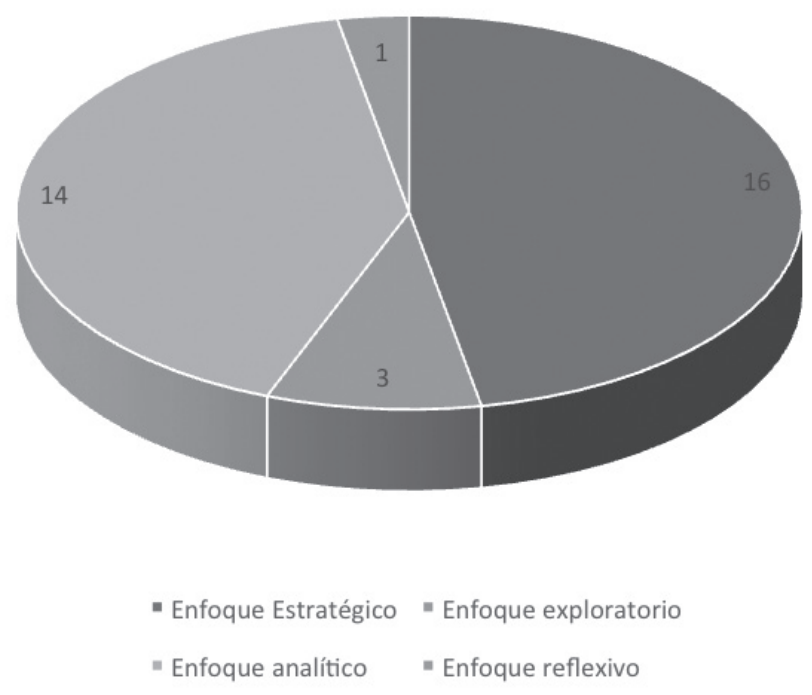

Figura 2. Número de preguntas según el enfoque en las investigaciones estudiadas

Actualmente hay dos tendencias fuertes en investigación en Lengua Castellana: la tendencia socio cognitiva y la tendencia semiodiscursiva. En esta última se tienen en cuenta:

Los procesos de conocimiento y de comportamiento en relación con la totalidad y la alteralidad y las dimensiones cognoscitiva, ética y estética desde las cuales la persona confiere sentido a la vida. Al integrar la concepción del lenguaje con su funcionamiento psicológico y social, la índole semiótica establece el papel del lenguaje en la representación de acuerdo con signos, códigos e intertextos; asimismo, complementa la producción de sentido desde las variables textual y contextual, comunes a la cultura de cualquier grupo humano (Cárdenas, 2004). 
Tabla 7. Clasificación de los proyectos pertinentes en las categorías de lo semiodiscursivo y lo sociocognitivo

\begin{tabular}{|c|c|c|}
\hline PERTINENTES & SEMIODISCURSIVO & SOCIOCOGNITIVO \\
\hline & $\begin{array}{l}\text { Renovación malla curricular plan de área Lengua } \\
\text { Castellana. } \\
\text { Reestructuración del plan de estudios de Lengua Cas- } \\
\text { tellana del Colegio Colombo ltaliano Michelangelo. } \\
\text { Enfoques y metodologías en la enseñanza de la gra- } \\
\text { mática de la Lengua Castellana en la Institución Edu- } \\
\text { cativa Normal Superior de Envigado. } \\
\text { Relación entre las imágenes y el texto de los cuentos } \\
\text { infantiles Eloísa y los bichos y Camino a casa del au- } \\
\text { tor Jairo Buitrago. } \\
\text { Las isotopías de ausencia y presencia en el cuento El } \\
\text { crimen (2006) de Efraím Medina Reyes mediante el } \\
\text { concepto de visión de mundo. } \\
\text { Dime qué ves y te diré qué escribes. } \\
\text { Recurso virtual de aprendizaje sobre la historia de la } \\
\text { lengua española. } \\
\text { Estimula tus sentidos: lee y escribe. } \\
\text { Es el momento de hablar, leer, escuchar y escribir. } \\
\text { La lectura en voz alta del cuento y la fábula, una } \\
\text { entrada al conocimiento. } \\
\text { Sistematización de los proyectos de prácticas profe- } \\
\text { sionales correspondientes a la Licenciatura de Hu- } \\
\text { manidades y Lengua Castellana (2005-2011). } \\
\text { La integración de los juegos pedagógicos virtuales en } \\
\text { el proceso de comprensión lectora. } \\
\text { Análisis semiótico de los lenguajes de un grupo de } \\
\text { jóvenes de Facebook. } \\
\text { Invitación a descubrir el mundo a través de la lectura. } \\
\text { Estrategias de promoción y animación a la lectura } \\
\text { enfocada en la comprensión lectora en grado tercero. } \\
\text { Orientación pedagógica y didáctica, para fortalecer } \\
\text { la competencia textual de menores en estado de } \\
\text { vulnerabilidad. } \\
\text { El discurso oral explicativo en el ámbito de la clase. }\end{array}$ & $\begin{array}{l}\text { Desarrollo de la com- } \\
\text { petencia interpretativa } \\
\text { a través del libro álbum } \\
\text { para grado tercero de } \\
\text { primaria. } \\
\text { Análisis semiótico de la } \\
\text { red social Facebook, per- } \\
\text { fil de vida. } \\
\text { Sin televisión y sin des- } \\
\text { treza los niños pierden } \\
\text { la cabeza. Los Simpson: } \\
\text { una guía para el ejercicio } \\
\text { de la escritura. } \\
\text { La formación inicial de la } \\
\text { escritura a través de un } \\
\text { libro de multimedia. } \\
\text { Producción de textos es- } \\
\text { critos a partir de historias } \\
\text { de vida desde el método } \\
\text { biográfico, en estudian- } \\
\text { tes de quinto de la Insti- } \\
\text { tución Educativa El Que- } \\
\text { bradón (Tolima). } \\
\text { Análisis de experiencias } \\
\text { educativas en los movi- } \\
\text { mientos sociales indíge- } \\
\text { nas del Cauca en Colom- } \\
\text { bia y Ecuador, un estudio } \\
\text { de casos. }\end{array}$ \\
\hline
\end{tabular}




\begin{tabular}{|c|c|c|}
\hline PERTINENTES & SEMIODISCURSIVO & SOCIOCOGNITIVO \\
\hline & $\begin{array}{l}\text { El cómic como estrategia didáctica para potenciar } \\
\text { la competencia comunicativa, en los estudiantes } \\
\text { del grado quinto de la Institución Educativa Privada } \\
\text { Campo Hermoso. } \\
\text { Desarrollo de competencias referidas a la compren- } \\
\text { sión e interpretación de textos mediante el comic } \\
\text { (Ásterix el galo) como elemento didáctico en los es- } \\
\text { tudiantes del grado cuarto del colegio Débora Arango } \\
\text { Pérez. } \\
\text { Propuesta club de lectura RELATA. Propuesta para el } \\
\text { fortalecimiento del hábito lector de los estudiantes } \\
\text { del programa LBHL de la Facultad de Educación de } \\
\text { la Corporación Universitaria Minuto de Dios. } \\
\text { La influencia del discurso docente de lenguaje en el } \\
\text { proceso lector. } \\
\text { La ortografía en los primeros años de escolaridad. } \\
\text { Prácticas de enseñanza de la ortografía en los grados } \\
\text { tercero y quinto. } \\
\text { Las prácticas ortográficas en la escuela Dulce } \\
\text { Sonrisa. } \\
\text { Las mil y una letras. } \\
\text { Lectura crítica en grado octavo de la Institución Félix } \\
\text { Naranjo San Diego (Samaná, Caldas). } \\
\text { La lectura y la escritura en la educación básica un } \\
\text { proceso de investigación. } \\
\text { El lenguaje escolar: lectura y escritura. } \\
\text { Evaluación de la lectura y la escritura. }\end{array}$ & \\
\hline
\end{tabular}




\section{PROYECTOS PERTINENTES EN LAS CATEGORÍAS DE LO \\ SEMIODISCURSIVO Y SOCIOCOGNITIVO}

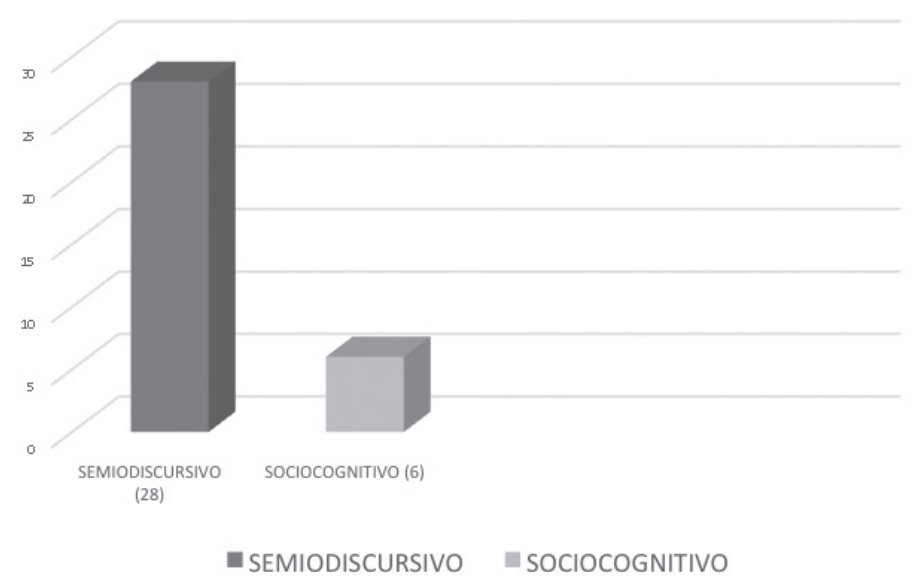

Figura 3. Clasificación de los proyectos pertinentes en las categorías de lo semiodiscursivo y lo sociocognitivo

\section{Conclusiones}

La consulta a los dominios de Internet de las universidades que ofrecen el programa permitió reconocer sus peculiaridades en distintos aspectos, incluyendo el plan de estudios y dentro de este, el área de la investigación formativa.

Las entrevistas realizadas facilitaron vislumbrar la intención de fomentar la cultura investigativa en los estudiantes, en algunos casos desde los primeros semestres. Es importante que los programas que aún no cuentan con prácticas dentro del campo específico, las implanten, puesto que resultan fundamentales para el maestro en formación, así como que vinculen los procesos de práctica pedagógica y de investigación.

Dos de las universidades participantes asumen el enfoque problematizador, otra, trabaja desde la teoría crítica, y la otra basa su propuesta en el enfoque praxeológico del profesor Carlos Juliao Vargas, en un esfuerzo de formar maestros investigadores, lo cual necesariamente implica un currículo flexible, integrador, 
crítico, participativo, de inclusión social, con apropiación de las TIC y reconocimiento del contexto, que atienda a la necesidad de implantar el conocimiento significativo y colaborativo.

La clasificación de los proyectos en pertinentes y no pertinentes, de acuerdo con su denominación, evidenció que se da una gran variedad de temáticas no relacionadas directamente con la Lengua Castellana, que no ofrecen ninguna relación directa con ella; tampoco con la educación básica, la didáctica o la pedagogía. Frente a los proyectos que logran una relación directa con el lenguaje, algunos poseen un fin de carácter disciplinar; y algunos establecen una relación secundaria con las temáticas propias del lenguaje donde Este se concibe como un medio y no como un fin; otros más establecen una relación profesional que indaga por la pedagogía del lenguaje.

Desde la perspectiva temática, la categoría de mediación docente (Tabla 5. Clasificación por categoría temática general de los proyectos revisados), dobla literalmente la categoría de subjetividad y aprendizaje, que ocupa un segundo lugar. Este dato muestra una preocupación mayor por la acción como docentes y como institución. También revela la importancia de los fenómenos de relación y comunicación en el aula entre los docentes y estudiantes, evidenciada a mediados del siglo XX. De igual forma, señala cómo desde el docente y la institución hay una preocupación mayor por evaluar, por diagnosticar y por recomendar estrategias para la acción docente. El hecho de que la categoría de subjetividad y aprendizaje siga en número, muestra el aprovechamiento de las experiencias de vida de los estudiantes. La temática de las TIC evidencia la gran preocupación contemporánea por el impacto de estas tecnologías y en la vida escolar, planteándose la manera como las mismas se pueden neutralizar en sus aspectos negativos y aprovechar para el aprendizaje.

El interés investigativo de la realidad motiva la generación de preguntas; sin embargo, en algunas de las investigaciones pareciera que las preguntas surgen desde el sentido común, y entonces se origina la investigación en un marco teórico que luego tratará de conectarse con las preguntas que no se hayan formulado conceptualmente.

La mayoría de los proyectos revisados son de corte cualitativo, por lo que se caracterizan por tratar de reconocer la naturaleza de las realidades del contexto y de intervenir las mismas. El investigador se obliga a acercarse a la realidad a estudiar, lo que logra a través de descripción, análisis e interpretación.

Por su parte, los métodos preferidos para abordar las investigaciones son los de corte asociativo, de modo tal que superan los métodos interrogativos, lo que podría parecer un poco contradictorio con el hecho del énfasis de la práctica dentro de las investigaciones, toda vez que los métodos asociativos en tanto que son indirectos implican 
procesos de inferencia, procesos analíticos más densos. Mientras que los métodos interrogativos someten los datos al abordaje, al análisis, al dimensionamiento y conteo de las respuestas concretas que debería ofrecer la investigación (Abric, 2001). La preferencia por los métodos asociativos tiene que ver con los paradigmas vigentes, tales como lo semiótico, lo discursivo, lo comunicativo..., que, en un momento dado, se imponen sobre la elección del enfoque de investigación. Estos paradigmas asociativos son herramientas que se le ofrecen a los estudiantes y que resultan válidas en sí mismas; pero que en una buena proporción de la investigación formativa aquí analizada parecieran estar en función del desarrollo analítico de la práctica, y entonces no se estaría tomando todo el potencial de estos paradigmas teóricos que van más allá de la pura respuesta a una necesidad específica, ni se estaría tomando en cuenta que estos paradigmas más bien revelan las condiciones con que se constituyen los modos de hacer de una sociedad, la razón de ser y los fundamentos de ese modo de hacer.

Dado que los proyectos de investigación formativa más que construir conocimiento tienen la función de formar a los estudiantes para ser capaces de desarrollar una investigación limitada y seria, el énfasis debe estar en la formación. En donde tiene que ser más importante aprender a hacer preguntas más delimitadas, sencillas, concretas, bien formuladas, en lugar de preguntas muy generales o vastas que difícilmente llevarían a algún lugar dentro de su formación.

\section{Referencias}

Abric, J. (Director). (2001). Representaciones sociales: aspectos teóricos y metodología de la recolección de las representaciones sociales. Prácticas sociales y representaciones. México: Ediciones Coyoacán.

Bachelard, G. (1976). La formación del espíritu científico: contribución a un psicoanálisis del conocimiento objetivo. Buenos Aires: Siglo XXI Editores.

Cárdenas, A. (2004). Semiolingüística aplicada y pedagogía del lenguaje. Recuperado de http://revistas.udistrital.edu.co/ojs/index.php/enunc/article/viewFile/2532/3558

Cerda, H. (2007). La investigación formativa en el aula. La pedagogía como investigación. Bogotá: Cooperativa Editorial Magisterio.

Corporación Universitaria Minuto de Dios. Consulta realizada abril 16 de 2014. Recuperado de http://www.uniminuto.edu/licenciatura-en-educacion-basica-con-enfansis-enhumanidades-y-lengua-castellana-en-bogota-principal 
Documento Maestro. (2010). Registro calificado de la Licenciatura en Educación Básica con énfasis en Humanidades y Lengua Castellana.

Hjelmslev, L. (1972). Prolegómenos de una teoría del lenguaje. Madrid: Gredos.

Hoyos, C. (2000). Un modelo para investigación documental: guía teórico-práctica sobre construcción de estados del arte con importantes reflexiones sobre la investigación. Señal Editora Ltda.

Lizarazo, D. y Andión, M. (2013). Símbolos digitales. Representaciones de las TIC en la comunidad escolar. México: Siglo XXI Editores.

Ministerio de Educación Nacional. (1994). Ley 115 de 1994. Recuperado de http://mineducacion.gov.co/1621/articles-85906_archivo_pdf.pdf

Ministerio de Educación Nacional. (1998). Decreto No. 272 de 1998. Recuperado de http://www.alcaldiabogota.gov.co/sisjur/normas/Norma1.jsp?i=1305

Ministerio de Educación Nacional. (2010). Resolución 5443 del MEN, emitida el 30 de junio de 2010. Recuperado de http://www.mineducacion.gov.co/1621/articles-238090_archivo_pdf_resolucion_5443.pdf

Pontificia Universidad Javeriana. Consulta realizada 14 mayo de 2014. Recuperado de http://www.javeriana.edu.co/carrera-licenciatura-en-educacion-basica

Ruiz, U. (Coord.). (s.f.). Lengua Castellana y Literatura: investigación, innovación y nuevas prácticas. Barcelona: Graó.

Tecnológico de Antioquia. Institución Universitaria. Consulta realizada 17 mayo de 2014. Recuperado de http://www.tdea.edu.co/index. php?option $=$ com_content\&view $=$ article\&id $=165$

Universidad de Antioquia. Consulta realizada 11 mayo de 2014. Recuperado de http://www.udea.edu.co/portal/page/portal/SedesDependencias/Educacion/B. InformacionFacultad/B.InformacionOrganizacional/Departamentos/CienciasArtes/ HumanidadesLenguaCastellana

Universidad de Córdoba. Consulta realizada 25 abril de 2014. Recuperado de http://www. unicordoba.edu.co/

Universidad Distrital Francisco Consulta realizada 30 abril de 2014. Disponible en José de Caldas. http://www.udistrital.edu.co/dependencias/tipica.php?id=34

Universidad San Buenaventura de Medellín. Consulta realizada 10 mayo de 2014. Disponible en http://web.usbmed.edu.co/usbmed/pregrados/educacion/p_ledu_basica_humanidades.htm

Universidad Santo Tomás. Consulta realizada 5 mayo de 2014. Disponible en http:// www.ustadistancia.edu.co/index.php/programas/educacion-a-distancia/pregrado/226facultadeducacion/452-licenciatura-en-educacion-basica-con-enfasis-en-humanidades-y-lengua-castellana 
Universidad Surcolombiana. Consulta realizada 28 abril de 2014. Disponible en http:// www.usco.edu.co/pagina/lengua-castellana 